Terragni, A. (2021):

- PORDOI 5 OFFICE

TING AND ULYSSES

Metszet, Vol 12, No 4 (2021), pp 30-35,

ttps://doi.org/10.33268/Met.2021.4.3

Received: 25 May 2021

Accepted: 18 June 202

Abstract: We have derived the organizational criteria of the facade from the study of drawings by the Dutch architect

van Doesburg. His works on the them of the diagonal, entitled studies for a

composition", which we have interpreted as

an expression of the diagonal line in relation to the orthogonal grid As in the stories of 5 also belongs

to a path of fantasy, which joins with the

weapons of colour and proportions the usual functional reduction of life. To one facade we assigned a memory function using slabs of black reflective Plexiglas. The fragments of Plexiglas indicate that matter and light are all that we have to express our creativity, our memories, and our astonishment of the boundaries of the fantastic.

Ulysses: a world with more 'water as possible.

A world of circular paths, transparent and

therefore unpredictable.

Travel. Mission. Appear, disappear, appear,

disappear, crystal ball and divine bosom ..

journey of a return to earth, return to earth

..of which we are still passengers .... and

responsible.

\section{KÉT ALKOTÁS}

DOBOZ AZ IDŐ JELÉVEL | PORDOI 5 IRODAHÁZ

\begin{tabular}{lll}
\hline ÉṔT́ÉSZ I ARCHITECT & FOTÓ I PHOTO & SZERZŐ I AUTHOR \\
Attilio Terragni & Paolo Rosselli, Attilio Terragni & Attilio Terrağni
\end{tabular}

_A homlokzatszervezessi elveket Theo van Doesburg holland epitész rajzainak elemzéséból vezettük le. Különösen az átlóval foglalkozó „Tanulmányok egy kompozícióhoz” [I] címú sorozatából, mely értelmezésünk szerint az átlós vonal es az or togonalis hàlo viszonyat fejezi ki. kisebb attöresekekel, amelyek vekonyak, sotetetek és mélyek, mint Lucio Fontana vásznain. 22] Belülrổ a megnyitàsok vilagosak es transzparensek, mert a 30 centimeteres magassag egybevảg az aluminiumkereten belül az üveg

__Az épüilet szerkezete is rendkívül fontos, mert lehetôvé teszi a belső tér teljesen szabad használatát. Az épületváz előregyarrtott oszlopokbol es gerendákból áll, olyan rendszerrel, mely akár 17 méteres fesztávot is lehetővé tesz. — Minden éptési anyag ,már bevezetett kataloguselem, csak nehanny elemet kellett módositani kisebb mertékben, anelkü hogy alapvetoen negvaltozott volna ipar jellegúk és àruk. Kulonoósen funkcionális és hatékony volt a meny-

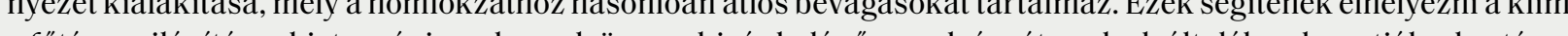
a futess, a világitás, a biztonsági rendszerek összes ki-és belépő szerelvényét, melyek általában lerontják a kortárs

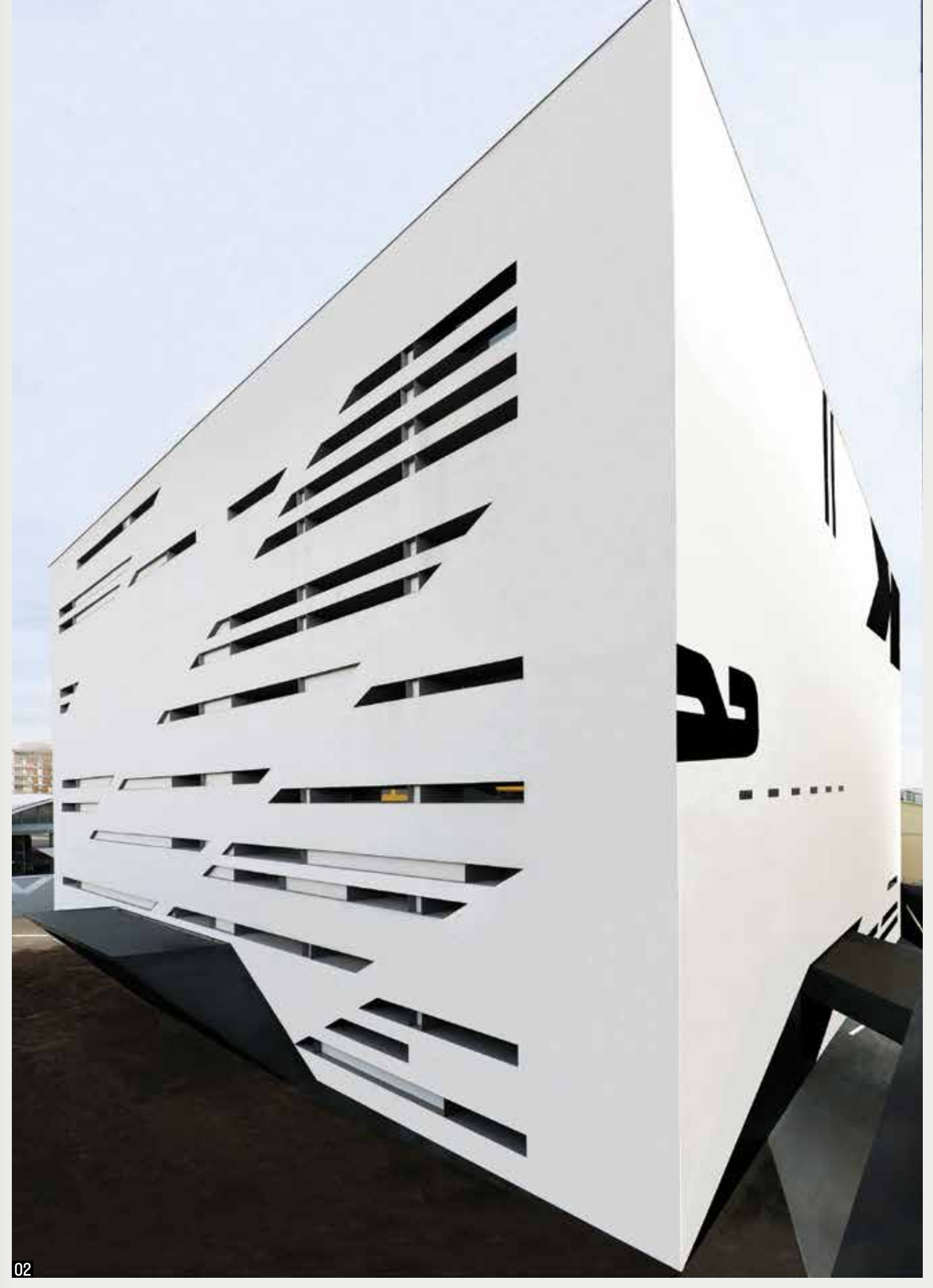

_Minden szint méretében és színeiben utal Dante Isteni színjátékának geometriájára (pokol, purgatórium, paradicsom), az alábbi analógiákkal: I. be- és kirakodás - nagy, sötét erdó; 2. pince, a tudás fája - pokol; 3. üzletek, szabad tér, labora-

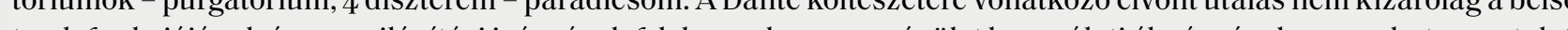
terek funkciojananak és megvilagitassi igènyének felel meg, hanem az épület hasznalati elmennyének, a munkatapasztalat-

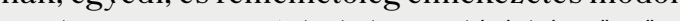
a színek és arányok segítségével az élet funkcionális egyszerüségéhez vezet. 


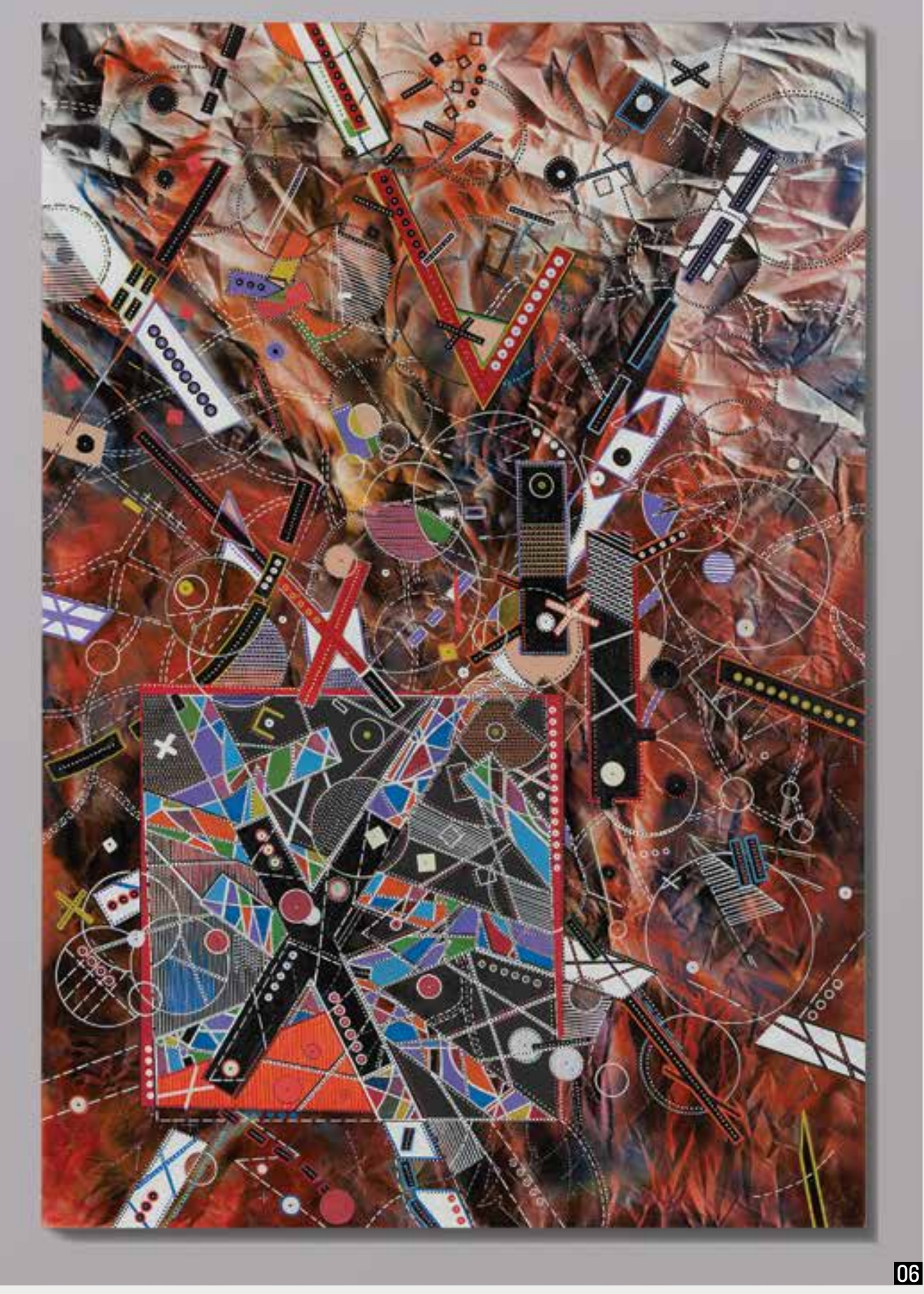

Körkörös, átlátszó, és ezért megjósolhatatlan utak világa
06-07 Idỏ / textúra, alkotás az Ulysses sorozatból

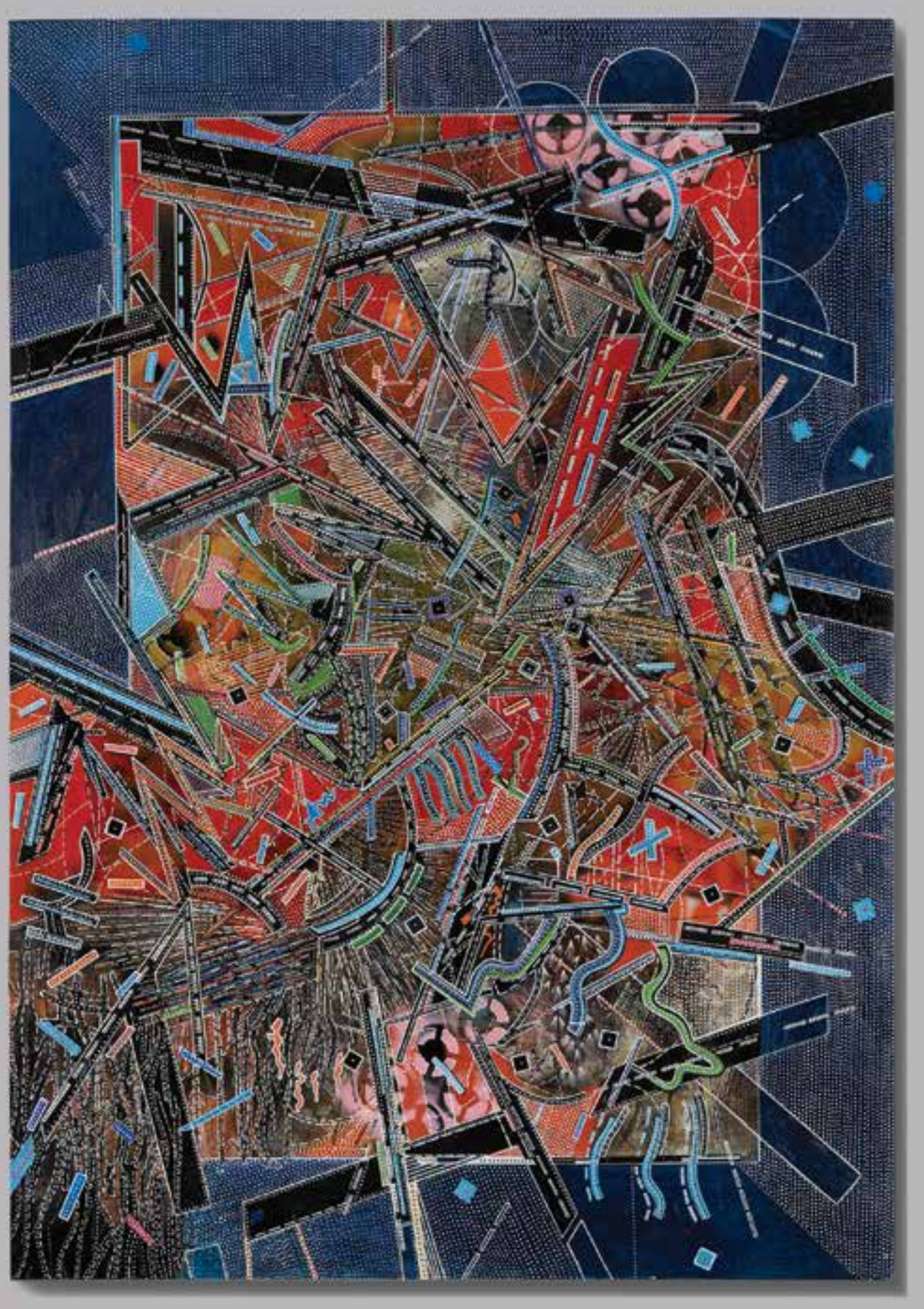

07

IRODALOM / REFERENCES

[1] Van Doesburg, Theo: Sudie für eine Komposition, MoMA, New York 1923

[2] Ferriani, Barbara: ,Lucio Fontana and Architecture”, Protection of Cultural Heritage, No 8 (December 2019), pp 113-121, D0I: : 10.35784/0dk.1073> [utolsó belépés: 2021-06-01].

[3] Orioli, Francesco: Ulysses in Dante's Paradise? - A conjecture, preprint, May 2021, hozzáférhetô: : https:I/Iwww researchğate.net/publication/351824480_Ulysses_in_Dante's_Paradise_-A_conjecture> [utolsó belépés: 202106-01], DOI: $<10.13140 / R G .2 .2 .23499 .31528>$ 